\title{
Detection of Chlorobenzene Derivatives Using Vacuum Ultraviolet Ionization Time-of-Flight Mass Spectrometry
}

\author{
Kenichi Tonokura, ${ }^{\dagger}$ Tomohisa NaKamura, and Mitsuo KoShI \\ Department of Chemical System Engineering, School of Engineering, The University of Tokyo, \\ 7-3-1 Hongo, Bunkyo, Tokyo 113-8656, Japan
}

\begin{abstract}
Vacuum ultraviolet single-photon ionization time-of-flight mass spectrometry (VUV-SPI-TOFMS) has been applied for the detection of chlorobenzene, $o$-dichlorobenzene, and $o$-chlorophenol as surrogates for polychlorinated dibenzo- $p$ dioxine/furans (PCDD/F). The photoionization mass spectra of these compounds appear to be fragmentation free in the ionization processes by the VUV-SPI at $10.2 \mathrm{eV}(121.6 \mathrm{~nm})$. Quantum chemical calculations support no fragmentation in the photoionization of chlorobenzene derivatives at around $10 \mathrm{eV}$. The absolute photoionization cross-sections of chlorobenzene, $o$-dichlorobenzene, and $o$-chlorophenol were estimated at $10.2 \mathrm{eV}$. The photoionization cross-section is an important parameter in the detection of chlorobenzene derivatives by the single-photon ionization technique. The detection limit for chlorobenzene is on the order of tenth parts-per-billion volume (ppbv) in the present experimental setup.
\end{abstract}

(Received April 21, 2003; Accepted May 30, 2003)

\section{Introduction}

Chlorinated aromatic compounds are important environmental pollutants, and have been suggested to be suitable surrogates for monitoring polychlorinated dibenzo- $p$-dioxins/furans (PCDD/F). One of the most effective methods to reduce $\mathrm{PCDD} / \mathrm{F}$ formation and the concentration in incinerator fuel gas is to control the operation of incinerators. Continuous on-line monitoring of toxic trace gas is essential to enable feedback control of incinerators. Quantitative analysis of PCDD/F by gas chromatography interfaced with a mass spectrometer takes more than one week due to complicated sampling and extracting processes. Instead of direct analysis of dioxin, therefore, realtime analysis of surrogates of dioxin is attracting attention.

Chlorobenzenes are correlated with the PCDD/F concentration in flue gas. ${ }^{1,2}$ Therefore, chlorobenzenes derivatives have been used as an indicator to estimate PCDD/F emission. ${ }^{2}$ Multi-photon ionization (MPI) methods are useful to detect chlorobenzenes. The resonance-enhanced multiphotonionization time-of-flight mass spectrometry (REMPI-TOFMS) technique has been used for the on-line measurement of

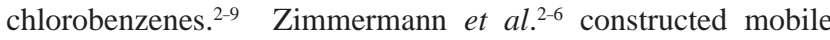
instruments for on-line monitoring of polyaromatic hydrocarbons and other aromatic species in the flue gas of industrial incineration plants. Oser et al. ${ }^{7-9}$ also performed REMPI mass spectrometry to detect chlorinated aromatic compounds. The detection limits of chlorobenzenes by REMPITOFMS were less than 100 parts per trillion volume (pptv). ${ }^{2-9}$ Imasaka et al. ${ }^{10,11}$ have been examined the pulse-width effect of a laser in the multiphoton ionization efficiency of halogenated

$\dagger$ To whom correspondence should be addressed.

E-mail: tonokura@chemsys.t.u-tokyo.ac.jp benzenes and phenols at $248 \mathrm{~nm}$. They indicated that an ultrashort laser pulse is very useful to improve the ionization efficiency for halogenated benzenes and phenols.

The threshold ionization technique has been widely used to avoid fragmentation in the ionization process. Vacuum ultraviolet single-photon ionization time-of-flight mass spectrometry (VUV-SPI-TOFMS) has been applied to diagnose several chemical systems. ${ }^{12-17}$ This technique provides the threshold ionization of chemical species. VUV-SPI is a soft ionization technique that can be adjusted to be nearly fragmentation free. Quantitative detection then becomes possible because the single-photon ionization cross-sections tend to be more uniform from molecule to molecule than those for multi-photon ionization. Recently, Muhlberger et al. ${ }^{18,19}$ applied VUV-SPI-TOFMS to the detection of aromatic species from automobile exhaust gas. It would, therefore, be expected that this technique could be used to detect dioxins and their precursors.

We demonstrated the detection of chlorobenzene, $o$ dichlorobenzene, and $o$-chlorophenol using time-of-flight mass spectrometry coupled with vacuum ultraviolet single-photon ionization. In the present work, the photoionization crosssections $\left(\sigma_{\text {ion }}\right)$ of halogenated benzenes and phenol at $10.2 \mathrm{eV}$ $(121.6 \mathrm{~nm})$ were estimated. The ionization potentials and appearance potentials leading to fragmentation were calculated using quantum chemical calculations. We now have a detection limit on the order of tenth ppbv for chlorobenzene.

\section{Experimental}

A schematic view of the experimental setup is shown in Fig. 1. The apparatus consists of a pulsed valve incorporated into a source chamber of the molecular beam machine, which is 


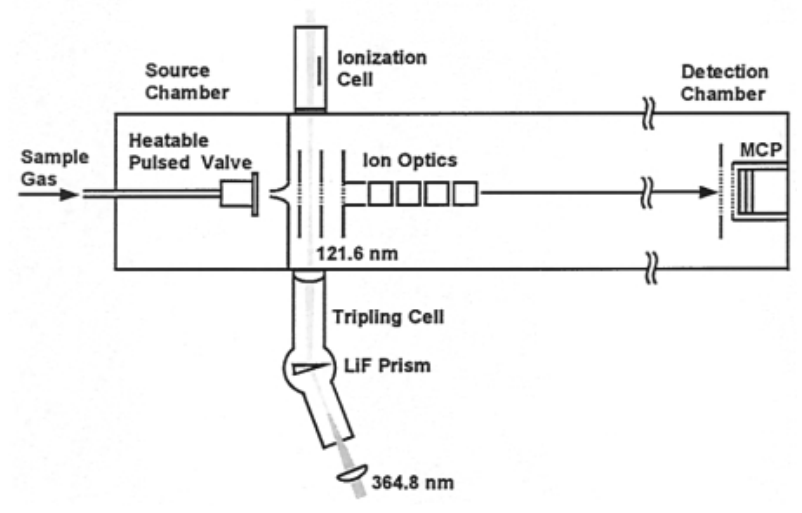

Fig. 1 Schematic diagram of the experimental apparatus.

equipped with a time-of-flight (TOF) mass spectrometer. The mass spectrometer can be operated as a Wiley-McLaren-type ${ }^{20}$ TOF mass spectrometer, described in detail elsewhere..$^{21,22}$ The field drift-free region was $130 \mathrm{~cm}$.

The sample gases were expanded from a pulsed valve (General Valve Series 9, $0.8 \mathrm{~mm}$ orifice diameter) with a stagnation pressure of 760 Torr and collimated by a skimmer $1.0 \mathrm{~mm}$ in diameter. The pulsed valve was heatable up to $200^{\circ} \mathrm{C}$ to minimize the wall adsorption effects. The distance between the ionization region and the pulsed valve was $45 \mathrm{~mm}$. A molecular beam was introduced into the TOF mass spectrometer. An Einzel lens and deflectors were located just above the ion acceleration regions.

Ionization was accomplished by photoionization at $10.2 \mathrm{eV}$. Coherent VUV laser light was obtained by frequency tripling in phase-matched $\mathrm{Kr} / \mathrm{Ar}$ gas mixtures adjusted to achieve the optimum phase matching. ${ }^{23}$ A frequency-tripling gas cell was sealed at the end opposite to an $\mathrm{MgF}_{2}$ lens ( $70 \mathrm{~mm}$ focal length at $121.6 \mathrm{~nm}$ ) by a fused silica window. A lens with a focal length of $15 \mathrm{~cm}$ was used to focus the output of an excimer pumped dye laser (Lambda Physik LPX 110 + Lambda Physik LPD 3002) in a cell containing rare-gas mixtures. The laser was operated at $10 \mathrm{~Hz}$. The typical laser intensity at $364.8 \mathrm{~nm}$ was 5 $\mathrm{mJ}$ pulse ${ }^{-1}$. The VUV and the residual dye laser light passed through a $\mathrm{MgF}_{2}$ lens and onto the molecular beam. The focusing $\mathrm{MgF}_{2}$ lens had a lower refractive index $(\eta=1.6275$ at $121.6 \mathrm{~nm}$ compared with $\eta=1.386$ at $364.6 \mathrm{~nm}$ ) at a longer wavelength; hence, the residual UV beam was mildly divergent. A LiF prism monochromator was also used to separate the VUV and the residual dye laser light. Figure 1 shows this experimental configuration. It consisted of a doubled coaxial cylinder; the outer cylinder was connected to a frequencytripling cell, while an inner one was installed in a prism on the cylinder axis and connected to a vacuum chamber via a $15 \mathrm{~cm}$ long arm. The dispersed UV light was blocked out by a plate. The spot size of the VUV laser light at the point of molecular beam was about $1 \mathrm{~mm}$. The VUV laser light was monitored using a NO contained photoionization cell. Because a NO molecule has an ionization potential of $9.24 \mathrm{eV}$, an incident VUV photon at $10.2 \mathrm{eV}$ can ionize the NO molecules. The resultant photocurrent by an ejected electron or ionized NO was monitored to measure the relative intensity of the VUV light $(\approx$ $10^{8-10}$ photons pulse $\left.{ }^{-1}\right) .^{23}$

The TOF signal was detected by a two-stage microchannel plate (MCP; Hamamatsu F4655-10). The output of the signal from the MCP was fed to a $500 \mathrm{MHz}, 1 \mathrm{GS} / \mathrm{s}$ digital oscilloscope (Tektronix TDS 520C) and transferred to a
Table 1 Ionization potentials of chlorobenzenes and the appearance potentials of $\mathrm{C}_{6} \mathrm{H}_{4} \mathrm{X}^{+}$ions

\begin{tabular}{|c|c|c|c|}
\hline & Ionization process & Experimental $^{a} / \mathrm{eV}$ & $\mathrm{G} 3 / \mathrm{eV}$ \\
\hline $\mathrm{C}_{6} \mathrm{H}_{5} \mathrm{Cl}$ & $\mathrm{C}_{6} \mathrm{H}_{5} \mathrm{Cl}^{+}+\mathrm{e}^{-}$ & 9.02 & 9.13 \\
\hline$\rightarrow \mathrm{C}$ & $\mathrm{C}_{6} \mathrm{H}_{5}^{+}+\mathrm{Cl}+\mathrm{e}^{-}$ & 12.6 & 12.47 \\
\hline \multirow[t]{2}{*}{$\mathrm{C}_{6} \mathrm{H}_{4} \mathrm{Cl}_{2}$} & $\mathrm{C}_{6} \mathrm{H}_{5} \mathrm{Cl}_{2}^{+}+\mathrm{e}^{-}$ & 9.06 & 9.08 \\
\hline & $\mathrm{C}_{6} \mathrm{H}_{4} \mathrm{Cl}^{+}+\mathrm{Cl}+\mathrm{e}^{-}$ & 12.9 & 12.91 \\
\hline \multirow[t]{3}{*}{$o-\mathrm{C}_{6} \mathrm{H}_{4} \mathrm{Cl}(\mathrm{OH})^{\mathrm{b}}$} & )$^{\mathrm{b}} \rightarrow o-\mathrm{C}_{6} \mathrm{H}_{5} \mathrm{Cl}(\mathrm{OH})^{+}+\mathrm{e}^{-}$ & $9.28^{c}$ & 8.70 \\
\hline & $\rightarrow \mathrm{C}_{6} \mathrm{H}_{4} \mathrm{OH}^{+}+\mathrm{Cl}+\mathrm{e}^{-}$ & $-----{ }^{d}$ & 12.92 \\
\hline & $\rightarrow \mathrm{C}_{6} \mathrm{H}_{4} \mathrm{Cl}^{+}+\mathrm{OH}+\mathrm{e}^{-}$ & $-----^{d}$ & 13.60 \\
\hline \multirow{2}{*}{\multicolumn{2}{|c|}{$\begin{array}{l}\mathrm{C}_{6} \mathrm{H}_{6} \rightarrow \mathrm{C}_{6} \mathrm{H}_{6}^{+}+\mathrm{e}- \\
\mathrm{NO} \rightarrow \mathrm{NO}^{+}+\mathrm{e}-\end{array}$}} & 9.24 & 9.31 \\
\hline & & 9.26 & 9.36 \\
\hline
\end{tabular}

a. Taken from Refs. $26-34$.

b. Cis-isomer.

c. Ionization potentials of $m$ - and $p$-chlorophenol are $8.65 \mathrm{eV}$.

d. No experimental data.

Pentium personal computer via a general purpose-interface bus. The TOF spectra were accumulated over 200 laser pulses (20 second measurement time).

A diluted mixture of chlorobenzene in He (Nippon Sanso) was used without further purification. Other samples were purchased from Aldrich and were used without further purifications. The premixed sample gases $(0.1 \%$ to $1 \%$ mixtures in the He buffer gas) were prepared and stored in glass bulbs, and then used to determine the ionization cross sections.

\section{Results and Discussion}

Mass spectra obtained by SPI at $10.2 \mathrm{eV}$

Table 1 gives the ionization potentials of chlorobenzene derivatives and the appearance potentials of $\mathrm{C}_{6} \mathrm{H}_{4} \mathrm{X}^{+}$ions. The ionization and appearance potentials calculated at the G3 level of theory ${ }^{24}$ using Gaussian 98 series of programs ${ }^{25}$ are also listed in Table 1. The energy differences between the experimental and G3 energies are less than $0.13 \mathrm{eV}$, except for $o$ chlorophenol. For $o$-chlorophenol, the cis-isomer is more stable than its trans-isomer. The difference in the heat of formation between cis- and trans-o-chlorophenol is $13.06 \mathrm{~kJ} \mathrm{~mol}^{-1}$ in the G3 energy. Thus, we only considered the cis-isomer for $o$ chlorophenol. The ionization potentials of the chlorobenzene derivatives are located around $9 \mathrm{eV}$. To our knowledge, the appearance potentials to form $\mathrm{C}_{6} \mathrm{H}_{5} \mathrm{Cl}^{+}$and $\mathrm{C}_{6} \mathrm{H}_{5} \mathrm{OH}^{+}$ions in the ionization of $o$-chlorophenol have never been reported. The calculated appearance potentials are listed in Table 1 . The appearance potentials of $\mathrm{C}_{6} \mathrm{H}_{4} \mathrm{X}^{+}$ions are more than $12 \mathrm{eV}$, which are much higher than the photon energy of $10.2 \mathrm{eV}$ used in the present study. ${ }^{26-34}$ Thus, fragmentation-free measurements of the mass spectra for chlorobenzene derivatives are expected in the SPI at $10.2 \mathrm{eV}$. Figure 2 shows the mass spectra of chlorobenzene, $o$-dichlorobenzene, and $o$-chlorophenol obtained by the SPI at $10.2 \mathrm{eV}$. The parent molecular ions were exclusively observed. The $70 \mathrm{eV}$ electron impact library spectra for chlorobenzene derivatives show fragmentation. ${ }^{34}$ In the present study, fragmentation-free mass spectra were obtained with the threshold ionization of these species at $10.2 \mathrm{eV}$ photon. As shown in Fig. 1 (a), the isotope distributions were observed with a ratio of 73:23 for masses of 112 and 114. This is in reasonable agreement with the isotope distribution calculated from the natural abundances, which are $75.8 \%$ for a mass of 112 and $24.2 \%$ for a mass of 114 . For $o$-dichlorobenzene and 

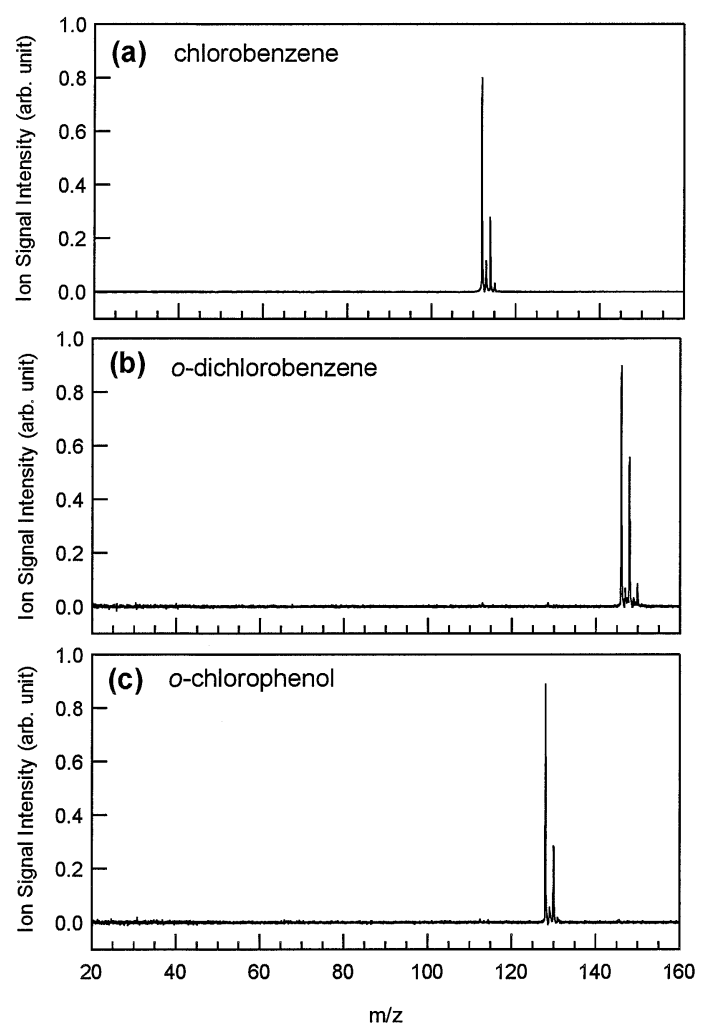

Fig. 2 Photoionization mass spectra of (a) chlorobenzene, (b) $O$ dichlorobenzene, and (c) $o$-chlorophenol obtained by single-photon ionization at $10.2 \mathrm{eV}$.

$o$-chlorophenol, the isotope distributions are also in reasonable agreement with the isotope distributions calculated from the natural abundances. The mass spectra of chlorobenzene, $O$ dichlorobenzene, and $o$-chlorophenol were not changed with two experimental configurations; one was no separation of the residual dye laser light at $364.8 \mathrm{~nm}$ and the VUV light at 121.6 $\mathrm{nm}$. The other used a LiF prism monochromator. Thus, the residual dye laser light at $364.8 \mathrm{~nm}$ was not affected in the ionization process under the present experimental conditions.

Figure 3 show the VUV laser power dependence of the molecular ion signals for chlorobenzene derivatives. The laser power dependencies were observed under the condition of no separation of the UV laser light and the VUV laser light. The ion signal intensity in the mass spectrum monochromatically increased with increasing pulse energy. The slopes in logarithmic plots of the ion signal intensity versus the VUV laser power are $1.04 \pm 0.01,1.05 \pm 0.02$, and $1.09 \pm 0.02$ for chlorobenzene, $o$-dichlorobenzene, and $o$-chlorophenol, respectively. These values indicate that the ionization process occurs in the single-photon process and that the ionization resulting from the multiphoton process by combining the VUV and UV lasers could be ruled out. No fragment ion was observed within the laser fluence considered in the present study.

\section{Photoionization cross-sections}

In the REMPI scheme, the detection sensitivity of halogenated benzenes is affected by the lifetime of the $S_{1}$ excited state, which is attributed to intersystem crossing by a spin-orbit interaction. $^{10}$ Therefore, there is the influence of the chlorine atoms substituted on a benzene ring in the REMPI. On the other hand, the detection sensitivity in the VUV-SPI scheme is

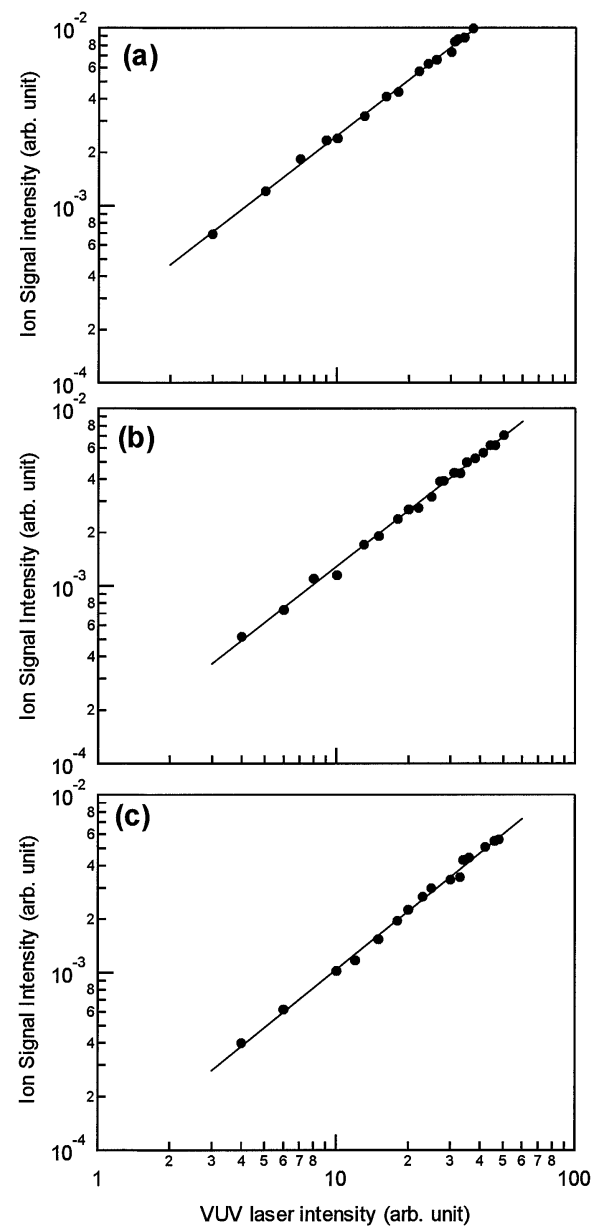

Fig. 3 Relationships between the intensities of molecular ions and the VUV laser pulse energy for (a) chlorobenzene, (b) $O$ dichlorobenzene, and (c) $o$-chlorophenol.

governed by the photoionization cross-section below the appearance potential leading to fragmentation. Thus, the absolute photoionization cross-section is an important parameter in trace gas detection by SPI mass spectrometry.

Photoionization processes of chlorobenzene derivatives have been well established by photoionization and photoelectron spectroscopy. ${ }^{26,27}$ Sergeev et al. ${ }^{26}$ measured the photoionization efficiency curves of chlorobenzene with the formation of a molecular ion and $\mathrm{a}_{6} \mathrm{H}_{5}{ }^{+}$ion. The photoionization efficiency curve of $o$-dichlrobenzene was measured by photoelectron spectroscopy. ${ }^{27}$ To our knowledge, however, the absolute photoionization cross-sections of chlorobenzene, $o$ chlorophenol, and $o$-dichlorobenzene have never been determined. We thus estimated the photoionization crosssections of these compounds at $10.2 \mathrm{eV}$. The same concentrations of $\mathrm{NO}$ and chlorobenzene derivatives were photoionized at $10.2 \mathrm{eV}$, and the signal intensities of molecular ions were measured. The photoionization cross-section of NO at $121.6 \mathrm{~nm}$ is known to be $2.0 \times 10^{-18} \mathrm{~cm}^{2}$ molecule ${ }^{-1} .{ }^{35}$ Using this value, the photoionization cross-sections of chlorobenzene derivatives are estimated by

$$
\sigma_{\text {ion }}(\mathrm{CB})=\sigma_{\text {ion }}(\mathrm{NO}) \frac{I(\mathrm{CB})}{I(\mathrm{NO})}
$$

where $\sigma_{\text {ion }}(\mathrm{CB})$ is the photoionization cross-section of the chlorobenzene derivative at $10.2 \mathrm{eV}, \quad \sigma_{\text {ion }}(\mathrm{NO})$ is the 
Table 2 Photoionization cross-sections $\left(\sigma_{\text {ion }}\right)$ of chlorobenzene species at $10.2 \mathrm{eV}$

\begin{tabular}{lcc}
\hline \multicolumn{1}{c}{ Species } & $\sigma_{\text {ion }} / 10^{-17} \mathrm{~cm}^{2}$ molecule & Ref. \\
\hline $\mathrm{C}_{6} \mathrm{H}_{5} \mathrm{Cl}$ & $2.6 \pm 0.4$ & This work \\
$\mathrm{C}_{6} \mathrm{H}_{4} \mathrm{Cl}_{2}$ & $1.3 \pm 0.1$ & This work \\
$\mathrm{C}_{6} \mathrm{H}_{4} \mathrm{Cl}(\mathrm{OH})$ & $2.1 \pm 0.2$ & This work \\
$\mathrm{C}_{6} \mathrm{H}_{6}$ & 0.8 & 36 \\
$\mathrm{NO}$ & 0.2 & 35 \\
\hline
\end{tabular}

photoionization cross-section of $\mathrm{NO}$ at $10.2 \mathrm{eV}$, and $I$ is the signal intensity of the molecular ion.

Table 2 gives the estimated photoionization cross-sections at $10.2 \mathrm{eV}$. The absolute photoionization cross-sections of chlorobenzene, $o$-chlorophenol, and $o$-dichlorophenol are $(2.6 \pm$ $0.4) \times 10^{-17},(1.3 \pm 0.1) \times 10^{-17}$, and $(2.1 \pm 0.2) \times 10^{-17} \mathrm{~cm}^{2}$ molecule ${ }^{-1}$, respectively. The photoionization cross-section of benzene at $10.2 \mathrm{eV}$ is $\mathrm{ca} .8 \times 10^{-18} \mathrm{~cm}^{2}$ molecule ${ }^{-1} .^{36}$ Thus, the detection sensitivity of chlorobenzene derivatives in the VUVSPI-TOFMS is expected to be higher than benzene derivatives (e.g. benzene, toluene, and xylene). Muhlberger et al. ${ }^{18}$ estimated the detection limits (DL) of NO and benzene by the SPI-TOFMS at $10.5 \mathrm{eV}(118 \mathrm{~nm})$. The ratio of the detection limits, $\mathrm{DL}(\mathrm{NO}) / \mathrm{DL}$ (benzene) $=6.9$, was derived by Muhlberger et al. ${ }^{18}$ This value is in reasonable agreement with the ratio of $\sigma_{\text {ion }}($ benzene $) / \sigma_{\text {ion }}(\mathrm{NO})=4$ at $10.5 \mathrm{eV}$.

\section{Estimate of the detection limit}

Figure 4 shows the SPI mass spectrum of 200 ppbv chlorobenzene calibration gas for a measurement time of $20 \mathrm{~s}$. The detection limit for a signal-to-noise $(S / N)$ ratio of 2 was estimated using the formula $\mathrm{DL}=2 \sigma \mathrm{c} / \mathrm{h}$, reported by Muhlberger et al., ${ }^{18}$ where $c$ is the concentration of the chlorobenzene standard; $\sigma$, the standard deviation of the noise between a mass of 105 and a mass of 111 , and $h$, the signal peak height at a mass of 112. The detection limit estimated using this formula is $20 \mathrm{ppbv}$. A series of measurements at calibration gases were also performed to estimate a calibration curve and the sensitivity limits for chlorobenzene. Figure 5 shows plots of the ion signal intensity versus the chlorobenzene concentration. The measurement time for each point in Fig. 5 was $20 \mathrm{~s}$. The plots show a good linear relation over a wide dynamic range of four orders magnitude. The detection limit for $S / N=2$ is located at around 14 ppbv.

We briefly tried the VUV-SPI-TOFMS detection of chlorobenzenes at $118 \mathrm{~nm}(10.5 \mathrm{eV})$ generated by frequency tripling at $355 \mathrm{~nm}$ laser light. The detection limit for chlorobenzenes by the SPI at $10.5 \mathrm{eV}$ was almost identical with the SPI at $10.2 \mathrm{eV}$. Since the ionization cross-sections at 10.2 and $10.5 \mathrm{eV}$ are almost the same, ${ }^{26}$ this result is reasonable. Muhlberger et al. ${ }^{18}$ estimated the detection limits in the $100 \mathrm{ppb}$ range for benzene derivatives by VUV-SPI-TOFMS at $10.5 \mathrm{eV}$. They did not optimize the phase-matching conditions for the third-harmonic generation process. Therefore, the detection limits in the present study are an order of magnitude higher than their values.

\section{Further improvement}

The detection limits of chlorobenzene derivatives by REMPITOFMS were reported to be less than 100 pptv. ${ }^{2-9}$ Zimmermann et al. $^{2}$ observed the chlorobenzene concentration in the 100 to 800 pptv region in a $22 \mathrm{MW}$ hazardous-waste incineration plant. The current VUV-SPI-TOFMS gives a detection limit of 20

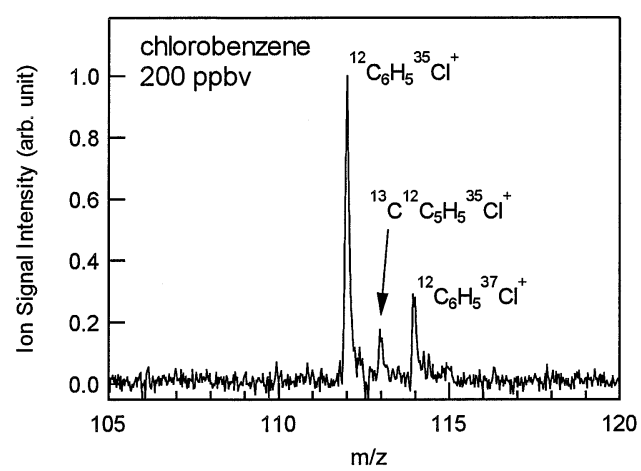

Fig. 4 Photoionization mass spectrum of a calibration gas mixture containing $200 \mathrm{ppbv}$ of chlorobenzene in helium to estimate the detection limit.

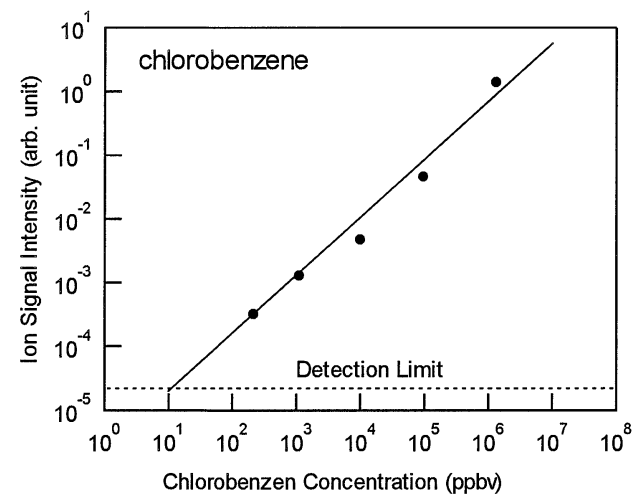

Fig. 5 Ion signal intensity versus a sample concentration plot for chlorobenzene.

ppbv for chlorobenzenes derivatives. The monitoring of trace of chlorobenzene derivatives using the VUV-SPI-TOFMS requires an improvement of the sensitivity by two orders.

The density $n(x)$ of chlorobenzene in the ionization region can be estimated by the following equation: ${ }^{37}$

$$
n(x)=n_{0} 0.15(x / D)^{-2},
$$

where $D$ is the nozzle diameter $(0.8 \mathrm{~mm}), x$ is the distance from the nozzle, and $n_{0}$ is the concentration for $x=0$. In the present apparatus, $n(x) / n_{0}$ is $4.7 \times 10^{-4}(x=45 \mathrm{~mm})$. If $x$ decreases to 15 $\mathrm{mm}$, the density of chlorobenzene in the ionization region increases up to $n(x) / n_{0}=4.3 \times 10^{-4}$. In the present apparatus, a Chevron assembly is used for MCP. The gain of the Z-stack assembly is an order of magnitude higher than that of the Chevron assembly. Improvements in sample introduction and the detector will give a two orders of magnitude higher sensitivity.

In summary, the VUV-SPI-TOFMS for chlorobenzene, odichlorobenzene, and $o$-chlorophenol at $10.2 \mathrm{eV}$ gives a fragmentation-free mass spectrum. The photoionization crosssection is an important parameter in VUV-SPI-TOFMS. Further improvement is necessary for monitoring the trace of chlorobenzene derivatives. In a future study we plan to construct an improved apparatus. 


\section{Acknowledgements}

The authors thank Prof. M. Kawasaki (Kyoto University) for useful comments. This work was supported in part by the Steel Industry Foundation for the Advancement of Environmental Protection Technology.

\section{References}

1. A. Aaune, U. Lenoir, U. Nikolai, and A. Kettrup, Chemosphere, 1994, 29, 2083.

2. R. Zimmermann, H. J. Heger, M. Blumenstock, R. Dorfner, K.-W. Schramm, U. Boesl, and A. Kettrup, Rapid Commun. Mass Spectrom., 1999, 13, 307.

3. M. Blumenstock, R. Zimmermann, K.-W. Schramm, and A. Kettrup, Chemosphere, 2001, 42, 507.

4. R. Zimmermann, H. J. Heger, R. Dorfner, U. Boesl, M. Blumenstock, D. Lenoir, and A. Kettrup, Combust. Sci. Technol., 1998, 134, 87.

5. H. J. Heger, R. Zimmermann, R. Dorfner, M. Beckmann, H. Griebel, A. Kettrup, and U. Boesl, Combust. Sci. Technol., 1998, 134, 87.

6. R. Zimmermann, H. J. Heger, A. Kettrup, and U. Nikolai, Fresenius J. Anal. Chem., 2000, 366, 368.

7. H. Oser, R. Thanner, and H.-H. Grotheer, Combust. Sci. Technol., 1996, 116, 567.

8. H. Oser, R. Thanner, H.-H. Grotheer, B. K. Gullett, D. Natschke, and K. Raghunathan, Combust. Sci. Technol., 1998, 134, 201

9. H. Oser, R. Thanner, and H.-H. Grotheer, Chemosphere., 1998, $9-12,2361$.

10. J. Matsumoto, C.-H. Lin, and T. Imasaka, Anal. Chem., 1997, 69, 4524.

11. T. Imasaka, Bunseki Kagaku, 2000, 50, 3.

12. U. Schuhle, J. B. Pallix, and C. H. Becker, J. Am. Chem. Soc., 1988, 110, 2323

13. M. S. de Vries and H. E. Hunziker, J. Photochem. Photobiol. A: Chem., 1997, 106, 31.

14. E. Nir, H. E. Hunziker, and M. S. de Vries, Anal. Chem., 1999, 71,1674

15. Y. J. Shi, X. K. Hu, D. M. Mao, S. S. Dimov, and R. H. Lipson, Anal. Chem., 1998, 70, 4534.

16. D. J. Butcher, Michrochem. J., 1999, 62, 354.

17. K. Tonokura and M. Koshi, Curr. Opin. Solid St. M., 2002,
$6,479$.

18. F. Muhlberger, R. Zimmermann, and A. Kettrup, Anal. Chem., 2001, 73, 3590.

19. F. Muhlberger, J. Wieser, A.Ulrich, and R. Zimmermann, Anal. Chem., 2002, 74, 3790.

20. W. C.Wiley and I. H. McLaren, Rev. Sci. Instrum., 1955, 26,1150 .

21. K. Tonokura, T. Murasaki, and M. Koshi, Chem. Phys. Lett., 2000, 319, 507.

22. K. Tonokura, T. Murasaki, and M. Koshi, J. Phys. Chem. $B, \mathbf{2 0 0 2}, 106,555$.

23. R. Hilbig and R. Wallenstein, IEEE J. Quantum Electron., 1981, $Q E-17,1566$.

24. L. A. Curtiss, K. Raghavachaii, P. C. Redfern, V. Rassolov, and J. A. Pople, J. Chem. Phys., 1998, 109, 7764.

25. M. J. Frisch et al., "Gaussian 98", Revision A.7, 1998, Gaussian, Inc., Pittsburgh PA.

26. Yu. L. Sergeev, M. E. Akopyan, F. I. Vilesov, and V. I. Kleimenov, Opt. Spektrosk., 1970, 29, 63.

27. B. Ruscic, L. Klasinc, A. Wolf, and J. Knop, J. Phys. Chem., 1981, 85, 1486.

28. S. Olesik, T. Baer, and J. C. Morrow, J. Phys. Chem., 1986, 90, 3563.

29. G. F. Crable and G. L. Kearns, J. Phys. Chem., 1962, 66, 436.

30. P. C. Burgers and J. L. Holmes, Int. J. Mass Spectrom. Ion Processes, 1984, 58, 15 .

31. V. V. Takhistov and D. A. Ponomarev, Org. Mass Spectrom., 1994, 29, 395.

32. G. I. Nemeth, H. L. Selzle, and E. W. Schlag, Chem. Phys. Lett., 1993, 215, 151.

33. K. Kimura, S. Katsumata, Y. Achiba, T. Yamazaki, and S. Iwata, "Handbook of HeI Photoelectron Spectra of Fundamental Organic Molecules", 1980, Japan Scientific Societies Press, Tokyo.

34. S. G. Lias, J. E. Bartmess, J. F. Liebman, J. L. Holmes, R. D. Levin, and W. G. Mallard, in NIST Chemistry WebBook, NIST Standard Reference Database Number 69, ed. P. J. Linstrom and W. G. Mallard, National Institute of Standards and Technology, 2003, Gaithersburg MD, USA (http://webbook.nist.gov).

35. K. Watanabe, J. Chem. Phys., 1954, 22, 1564

36. T.-A.Carlson, P. Gerard, M. O. Krause, F. A. Grimm, and B. P. Pullen, J. Chem. Phys., 1987, 86, 6918.

37. D. R. Miller, "Atomic and Molecular Beam Methods Vol. I”, ed. G. Scoles, 1988, Oxford, New York, 14. 